\title{
Rosa Campusano: patriota comprometida vista por la tradición de Palma y el historiador Germán Leguía
}

\author{
Arnaldo Mera Ávalos \\ Instituto Ricardo Palma \\ Arnaldo_mera@hotmail.com
}

\section{Resumen}

A partir de la revisión de la tradición Rosa Campusano, "La Protectora" podremos reconstruir su participación en la labor de propaganda y difusión de la causa patriota antes y después del arribo de la Expedición Libertadora del General San Martín en 1820, consultando la obra del destacado historiador Germán Leguía y Martínez. Luego, veremos de qué manera el nuevo estado constituido denominado Protectorado la condecoró por dicha labor en 1822, así como las opiniones vertidas por don Ricardo Palma al respecto.

Palabras clave: Independencia, protectorado, mujer, género, heráldica, diarios, S. XVIII y S. XIX.

\section{Abstract}

From the review of the tradition Rosa Campusano, "La Protectora" we will be able to reconstruct her participation in the work of propaganda and dissemination of the patriotic cause before and after the arrival of the Liberation Expedition of General San Martin in 1820 consulting the work of the Outstanding historian German Leguia and Martinez. Finally we will see how the new state constituted and denominated Protectorate decorated by this work in 1822 and the opinions expressed by don Ricardo Palma in this respect.

Keywords: Independence, protectorate, women, gender, heraldic, daily, 18th century and 19th century. 


\section{Arnaldo Mera Ávalos}

Historiador e investigador, bachiller en Derecho por la Pontificia Universidad Católica del Perú. Ha publicado artículos en libros y revistas. Licenciado en Historia y egresado de la Maestría en Historia de la PUPC. 


\section{Rosa Campusano ardiente partidaria de la Patria}

Abordaremos un tema nunca trabajado: el desempeño por la causa patriota, desde el punto de vista histórico, de una mujer sobre la cual Ricardo Palma habla en una tradición que lleva su nombre y, además, su sobrenombre. Dicho texto nos ofrece su lugar y año de nacimiento, acaecido en Guayaquil en 1798. Palma nos cuenta, también, que fue testigo de excepción. A la edad de trece años, en 1846, conoció en persona a la protagonista de su tradición, pues era la madre de un amigo con el que estudiaba:

Era ella una señora que frisaba en los cincuenta, de muy simpática fisonomía delgada, de mediana estatura, color casi alabastrino, ojos azules y expresivos, boca pequeña y mano delicada. Veinte años atrás debió de haber sido mujer seductora por su belleza y gracia y trabucado el seso a muchos varones en ejercicio de su varonía. Se apoyaba para andar en una muleta con pretensiones de bastón. Renqueaba ligeramente. Su conversación era entretenida y no escasa de chistes limeños (...).

El tradicionista nos cuenta, además, dónde vivía:

En los altos del edificio en que está situada la Biblioteca Nacional y cuyo director, que lo era por entonces el ilustre [Francisco de Paula González] Vigil, concedía habitación gratuita a tres o cuatro familias que habían venido a menos. En un departamento compuesto de dos cuartos.

Nos dice el tradicionista:

En 1817 llegó a Lima la Rosita en compañía de su amante, acaudalado español que barbeaba medio siglo (...) En breve los elegantes salones de la Campusano en la Calle de San 
Marcelo fueron el centro de la juventud dorada. Los condes de la Vega del Ren y de San Juan de Lurigancho, el marqués de Villafuerte, el vizconde de San Donás y otros títulos partidarios de la revolución; Boqui, el caraqueño Cortinez, Sánchez Carrión, Mariátegui y muchos caracterizados conspiradores en favor de la causa de la Independencia formaban la tertulia de Rosita que con el entusiasmo febril con que las mujeres se apasionan de toda idea grandiosa se hizo ardiente partidaria de la Patria.

La importancia del desempeño femenino en la difusión de la causa patriota es innegable y ello lo afirma el más importante historiador de aquel período, Germán Leguía, quien indica que las calles de Lima amanecían literalmente

Regadas de papeles (...) contrarios al régimen y que estos papeles como un reguero de pólvora corrían, encendiendo la opinión a lo largo de la costa del virreinato (...) distinguiéronse, en esa arriesgada y proficua labor de investigación, zapa y publicidad las mujeres de Lima, cuyo sexo no influyó, por cierto, en que se suspendieran o aminoraran las crueles y temerarias explosiones de rigor, castigo y venganza de las autoridades realistas".

Mendiburu nos dice que por el mes de junio de 1819 fueron apresadas las recalcitrantes patriotas doña Mercedes Nogareda y doña Manuela Estacio. Continúa aseverando Leguía y Martínez:

(...) hubo ocasión en que se puso en arresto a doce o catorce mujeres, convencidas de conspirar en pro del separatismo, de desparramar nuevas alarmantes, y de corromper a las tropas reales induciendo a la rebeldía y a la deserción. La medida en vez de aterrar estimuló el patriotismo de la mujer limeña que resultó el mayor de los enemigos de la 
dominación peninsular. En torno de las señoras y señoritas de la nobleza capitalina, a cuya cabeza brillaban la marquesa de Castellón (Clara de Buendía y de Carrillo), las dos Guisla (Hermenegilda, condesa de la granja, y María Simona), la condesa de la Vega del Ren (Josefa de la Fuente y Carrillo de Albornoz de Vázquez de Acuña) y la marquesa de San Miguel [de Hijar] (Josefa Messía y Aliaga de la Fuente), actuaban acuciosa y eficazmente las más brillantes estrellas del cielo de Lima y un sinnúmero de auxiliares de todas las clases y condiciones (...).

Entre las que también figura Rosa Campusano, a quien el historiador denomina "la tentadora Dalila de San Martín”.

Afirma nuestro insigne tradicionista:

Desde que San Martín desembarcó en Pisco, doña Rosa que a la sazón tenía por amante al general [arequipeño] don Domingo Tristán, entabló activa correspondencia con el egregio argentino. Tristán y La Mar que era otro de los apasionados de la gentil dama, servían aún bajo la bandera del rey, y acaso tuvieron en presencia de la joven expansiones políticas que ella explotara en provecho de la causa de sus simpatías.

Una nota a pie de página en el tomo III de la Historia del Protectorado del historiador Leguía y Martínez, va más allá de lo afirmado por Palma al decir:

Relata Mariátegui que cuando San Martín desembarcó en nuestra costa recibieron los patriotas limeños un paquete que contenía comunicaciones del general del Ejercito Libertador dirigido a los jefes americanos que tenían las desgracia de servir en las filas del ejército opresor (...) uno de los que recibió el oficio fue el general La Mar 
Luego indica que fue Rosa Campusano quien "tomó ese oficio", fue a Palacio y, "con el pretexto de hacerle una solicitud a La Mar, le pidió que la oyese en secreto, en lo que La Mar convino". Y agrega que "la Campusano dejó, sobre el sofá, en que estuvo sentada el consabido pliego, que el general encontró poco después que la interlocutora se retiró, evacuada su fingida pretensión". Por supuesto, La Mar

Leyó su oficio y a nadie habló una sola palabra, procediendo con dignidad y como caballero; conducta que observaron Llanos, Otermin y demás jefes americanos (excepto Landázuri) a quienes la propia Campusano y otras patriotas entregaron las respectivas comunicaciones llegadas del cuartel general de Pisco. (Mariátegui, 1869: 55-56)

Continua Leguía y Martínez afirmando:

La aseveración de Mariátegui, en este como en otros casos, es en extremo fidedigna y valiosa; tanto más cuanto que el magistrado en cuestión afirma haber sido él mismo quien había hecho entregar a La Mar el oficio de San Martín

valiéndose de la Campusano como ya se dijo (Mariátegui, 1869). Este historiador repite la misma información, sin dar su opinión, en la nota 38 del tomo II.

Sobre el paso del Batallón Numancia dice Leguía y Martínez que fue

Gozosamente recibido por sus correligionarios y conmilitares realistas, hízose pronto objeto de las complacencias virreinales; tanto más cuanto que en presentaciones públicas ejercicios y maniobras resultó ser una unidad inmejorable, no sólo por la disciplina y la organización, la perfecta euritmia y la marcialidad sino más que todo por la pericia y destreza. 
Mendiburu, por su lado, afirmó:

Era un crecido de jóvenes robustos, en lo general de buena estatura bien uniformados con adornos de plata en la banda y los morriones de sus brillantes compañías de preferencia; y cuéntase que en cierto simulacro "los fuegos de ese batallón admiraron de tal modo que el coronel del regimiento del Infante [don Carlos de Borbón], don Juan Antonio de Monet, dirigióse al Comandante Delgado elogiándole el armamento; y que este contestó: superiores son los que lo manejan.

Continúa diciendo Leguía y Martínez que poco duró aquella complacencia y engreimiento porque los patriotas limeños diéronse a la catequización de los numantinos, siguiéndolos aquellos o sus emisarios. Citando a Paz Soldán (1868: 101): “(...) a donde quiera que iba el batallón por causa de servicio, procurando hacerse de la confianza de la oficialidad y de la tropa". Leguía y Martínez da nombres de varones comprometidos en dicha labor "secundados todos eficazmente por mujeres tan denodadas", entre las cuales menciona a Rosa Campusano. Por su parte, Palma afirma:

Don Tomás Heres prestigioso capitán del batallón Numancia, instado por dos de sus amigos sacerdotes oratorianos para afiliarse a la buena causa, se manifestaba irresoluto. Los encantos de doña Rosa acabaron por decidirlo y el Numancia, fuerte de 900 plazas pasó a incorporarse entre las tropas republicanas [de la Expedición Libertadora]. La causa de España en el Perú quedó desde ese momento herida de muerte.

Palma no exagera con esta última aseveración, además escribió:

Decíase también que el virrey La Serna quemaba el incienso de galanteo ante la linda guayaquileña y que no pocos 
secretos planes de los realistas pasaron así de la casa de doña Rosa al campamento de los patriotas en Huaura (...) En una revolución que a principios de 1821 debía encabezar en la fortaleza del Callao el comandante del batallón Cantabria, don Juan Santalla, fue doña Rosa la encargada de poner a este jefe en relación con los patriotas. Pero Santalla que era un barbarote de tan hercúleo vigor que con sólo tres dedos doblaba un peso fuerte se arrepintió en el momento preciso y rompió con sus amigos, poniendo la trama en conocimiento del virrey, si bien tuvo la hidalguía de no denunciar a ninguno de los complicados.

De este modo, el tradicionista continúa añadiendo información sobre otros hechos loables para la causa de la patria realizados por doña Rosa.

Leguía y Martínez en el tomo II de su magna obra, la define como

La hermosa y astutísima (...) Aspasia de la revolución: en cuyo atrayente domicilio repleto de encantos reuníanse y vaciaban sus más íntimos secretos personales y políticos los altos jefes españoles; secretos que inmediatamente pasaban a noticia de los independientes, y, por su conducto, al de San Martín; atrevida conductora de comunicaciones importantes al palacio de Pizarro y a sus propias oficinas; mujer irresistible que, prendada del prócer de Yapeyú supo inspirarle pasión duradera, recóndita y ferviente a la par dulce y perniciosa para el corazón del gran libertador del sur.

Así mismo, en el tomo IV expone cómo el general San Martín conoció a Rosa antes de su ingreso a Lima, cuando se estableció en La Legua luego de la retirada del virrey La Serna rumbo a la Sierra, efectuada el seis de julio de 1821 . El general fue saludado la noche del diez de julio por un grupo de damas distinguidas 
de la élite limeña. Entonces Rosa Campusano hizo su aparición, y es descrita por Leguía y Martínez como

(...) una mujer alta, hermosa y agraciada, que, sollozante por la emoción, échase en su brazos, cual si ya le fuesen conocidos y amados; y clavada en ellos apenas si acierta a articular y repetir estas palabras: iMi General! iMi General! San Martín la oprime benévolo y luego la contempla embebecido. La desconocida baja los ojos ante la penetrante mirada del héroe.

-Serenaos, no hay por qué llorar-le dice este último. Apártala suavemente $\mathrm{y}$, olvidando su gravedad habitual, vencido un momento; herido por el dardo de tantos atractivos, palpando secretamente la ardencia de aquellos ojos, tanto más hermosos cuanto se muestran más nublados por las lágrimas, murmura a media voz: ¿Permitiríais expresaros mi gratitud con un beso? Pero refrenando esa extraordinaria expansión suya, que pasa como un relámpago; ordena a su ayudante darle el brazo y acompañarla hasta afuera; y se detiene a contemplarla con visible interés mientras la incógnita se retira. ¿Quién es esa mujer sentimental, cuyo silencio y cuyos sollozos, más arrebatadores que la elocuencia misma, han bañado en extraña alegría y súbita luz las horas borrosas y las pesadas expansiones de esta noche sublime? Es Rosa Campusano, perla del Guayas, espíritu romántico, carácter novelesco, corazón imantado por la fama, apasionado de la gloria, idólatra del heroísmo, prototipo de aquella belleza marfilina que distingue a las beldades de su patria; pálida excelsitud en cuyas pupilas chispean el fuego del amor y la llama de la idealidad; halago ardiente, tentación satánica, predestinados a derretir la nívea rigidez del guerrero paciente y calculador, y a poner nuevos y más apretados grillos en la ya enfermiza energía y 
actividad decadente del Aníbal de los Andes. Eran las diez y media de la noche.

\section{Rosa Campusano y la innominada Orden de las Damas patriotas:}

Sabemos que la población de la ciudad de Lima cuando fue capital del virreinato y sede de la corte tuvo pleno conocimiento de la existencia de las órdenes nobiliarias de caballería a través de la gaceta de gobierno y de la publicación inclusive de un libro impreso en 1815. El gusto de la élite y nobleza limeña por acceder a las mismas está expuesto a través del número de aquellos que pertenecieron a las seis órdenes en los últimos 21 años de dominio hispano, listado realizado por el insigne historiador Lohmann Villena. Así mismo con la creación de tres nuevas órdenes durante el reinado de Fernando VII: San Fernando en 1811, San Hermenegildo en 1814 e Isabel La Católica en 1815, hizo que el tema fuese de actualidad en Lima. Esto conllevó a que, cuando se dio el cambio de régimen y el gobierno del Protectorado creó la Orden del Sol en octubre de 1821, no fuese un hecho dramático. Por el contrario, la publicación del decreto y de hechos vinculados a la misma, entre octubre y diciembre de 1821 , en la gaceta de gobierno mantuvo debidamente informada a toda la población limeña. Por ello no sorprendió que el 11 de enero de 1822 el ministro de Relaciones Exteriores del Protectorado, Bernardo Monteagudo, crease una innominada orden de mujeres, independiente de la Orden del Sol, pues, como bien dice Leguía y Martínez (197 l: 227): “(...) no la subordinaba ni hacía referencia a ella". A su vez, nos dice que Mitre la llamó Orden Femenina, "paralela" a la del Sol, y, según refiere, "se distribuyó con más galantería que discreción haciéndola extensiva a las más bellas y amables damas, lo que dio motivo a murmuraciones mujeriles, que el tiempo no ha apagado". Lo cierto es que también la población femenina 
limeña tenía conocimiento, desde hacía casi 30 años, de que las mujeres podían ser agraciadas con una orden nobiliaria, ya que en 1792 Carlos IV creó para su esposa la Real Orden de la reina María Luisa, y ello apareció publicado en la Gazeta de Madrid de abril de aquel año ${ }^{1}$ y que la población limeña pudo leer o enterarse de oídas cuando dicha Gazeta llegase a la corte virreinal en su momento; pero además volverá a saber de la misma orden a través de la Gaceta de Gobierno de Lima en mayo de $1817^{2}$, cuando se publicó un decreto del 25 de octubre de 1816 en el cual se le daban las mismas prerrogativas y preeminencias de esta orden femenina a la recién desposada reina de España, la infanta María Isabel de Braganza, esposa de Fernando VII, último soberano del Perú; con lo cual creemos que no fue novedad para las limeñas la aparición en la antigua corte virreinal de una orden femenina que buscase premiar la causa de la patria con un rango nobiliario, aún vigente para quienes nunca pudieron acceder en su momento a la orden hispana debido a la distancia. Se publicó un anuncio el 23 de enero, y el 6 de febrero de 1822 se publicó la relación de todas las patriotas distinguidas ${ }^{3}$ en la cual aparece Rosa Campusano, que bien merecida tenía tal distinción, y es un dato que consignó en su momento nuestro ilustre tradicionista de la siguiente manera:

Organizada ya la orden del Sol, San Martín, por decreto de 11 de enero de 1822, creó ciento doce caballeresas seglares y treinta y dos caballeresas monjas, escogidas entre las más notables de los trece monasterios de Lima. Entre las primeras se encontraban las condesas de San Isidro y de la Vega y las marquesas de Torre Tagle, Casa-Boza, Castellón

I Gazeta de Madrid No 33 del martes 24 de abril de 1792 p. 261.

2 Gaceta de Gobierno de Lima No 29 del jueves I de mayo de 1817 pp.231-232.

3 Gaceta de Gobierno de Lima No 7 del miércoles 23 de enero de 1822 pp. 3-4 y Gaceta de Gobierno de Lima No 11 del miércoles 6 de febrero de 1822, pp. 3-4 
y Casa Muñoz. El viajero Stevenson que fue secretario de Lord Cochrane y que como tal participara del encono de su jefe contra San Martín, critica en el tomo III de su curiosa y entretenida obra impresa en Londres en 1829, Historical and descriptive narrative of twenty years residence in South America que el protector hubiera investido a su favorita la Campusano con la banda bicolor (blanco y rojo), distintivo de las caballeresas. Esta banda llevaba en letras de oro la inscripción siguiente: Al patriotismo de las más sensibles. Paréceme [dice Palma] que en los albores de la Independencia la sensiblería estuvo muy a la moda. Sin discurrir sobre la conveniencia o inconveniencia de la creación de una Orden antidemocrática y atendiendo al hecho encuentro injusta la crítica de Stevenson. Es seguro que a ninguna otra de las caballeresas debió la causa libertadora servicios de tanta magnitud como los prestados por doña Rosa. En la hora de la recompensa y de los honores no era lícito agraviarla con ingrato olvido.

\section{Finaliza su tradición diciendo:}

Con el alejamiento de San Martín de la vida pública se eclipsa también la estrella de doña Rosa Campusano (...) Posteriormente y cuando los años y acaso las decepciones, habían marchitado a la mujer y traídola a condición estrecha de recursos para la vida, el Congreso del Perú asignó a la caballeresa de la Orden del Sol [se equivoca el tradicionista al denominarla de esta manera pues fue una orden innominada como ya vimos al inicio de este acápite] una modesta pensión. La Protectora murió en Lima por los años de 1858 a 1860. 


\section{Consideraciones finales}

Debemos tener muy presente que la tradición fue en un inicio un testimonio vivencial para luego narrarnos hechos históricos ya que por lo expuesto constatamos que Palma no solo tuvo la oportunidad de conocer al personaje de su tradición y describirlo, sino que se documentó de una manera concienzuda y eficaz para narrarnos la vida política de una patriota guayaquileña vinculada de manera innegable a la historia de la independencia peruana. También hemos podido demostrar cómo lo afirmado por el tradicionista se corrobora con la investigación del connotado historiador Germán Leguía y Martínez, en su obra Historia del Protectorado, obra escrita al cumplirse el centenario de nuestra independencia en 1921 , pero que, como bien sabemos, quedó inédita por más de medio siglo hasta que en 1971 la sacó a la luz Alberto Tauro del Pino. Queda aún por escribirse una biografía de Rosa Campusano y no debemos olvidar que, si no fuese por nuestro insigne tradicionista, el desempeño y la vida política de la "Aspasia de la revolución" hubiesen quedado en el olvido, ya que la obra de Leguía Martínez resulta poco conocida por el público general respecto de las Tradiciones Peruanas.

\section{Bibliografía}

De La Puente Candamo, J.A. (1993). La Independencia. Historia General del Perú. Lima: Ed. Brasa, vol. VI.

Leguía y Martínez, G. (1971). Historia del Protectorado. Colección documental de la Independencia del Perú. Lima: Comisión Nacional del Sesquicentenario de la Independencia del Perú, vol. II, III, IV y V. 
La Orden del Sol, cambio y continuidad del antiguo régimen al Protectorado (octubre 1821 - enero 1822) (2014). Tiempos 9, Revista de Historia y Cultura. Lima: Taller de Investigaciones Históricas, Seminario de Historia Rural Andina, pp. 131-150.

Mariátegui, J. F. (1869). Anotaciones a la Historia del Perú Independiente de don Mariano Felipe Paz Soldán. Lima.

Mera Ávalos, A. (2005). Cuando la patria llegó a la capital: el miedo ante el advenimiento de la Independencia 1820-1821. El Miedo en el Perú, siglos XVI al XX. Rosas Lauro, C. (comp). Lima: Pontificia Universidad Católica del Perú, pp. 185-231.

Palma, R. (1964). Tradiciones Peruanas Completas. Madrid: Aguilar.

Paz Soldán, M. F. (1868). Historia del Perú Independiente. Vol I. Lima, Imprenta Alfonso Lemale.

Tauro del Pino, A. (2001). Enciclopedia ilustrada del Perú. Lima: PEISA, vol. IX. 